\title{
RELATIONSHIP BETWEEN SUBJECTIVE HAPPINESS AND WISDOM OF RETIRED PROFESSIONALS
}

\section{G. SWARUPA RANI, S. SRAVANTHI REDDY \& T. ASHA JYOTHI}

Research Scholar, Department of HDFS, C. H. Sc, Hyderabad, Telangana, India

\begin{abstract}
The aim of the study is, to find out the relationship between subjective happiness and wisdom among retired professionals. The current article presents the relationship between subjective happiness and wisdom in terms of studying the mean differences in wisdom based on subjective happiness level and also studying the type of relationship exists between these two. To conduct the study a sample of 180 retired professionals were selected. To measure the subjective happiness, a scale was developed by Sonja Lyubomirsky and Heidi S. Lepper (1997) used. To measure the wisdom of retired professional, a scale was developed and used called Self-Measured Wisdom Scale (SMWS). The results of the study indicated that, the age groups and subjective happiness are not significantly associated, which indicates there were no significant differences in subjective happiness based on age group. The mean differences seen in dimensions of wisdom were significant in relation to subjective happiness score, however subjective happiness was found to be positively and significantly related with wisdom's components. Therefore it was found from the study that subjective happiness was reflected to be an essential aspect and positively associated with wisdom of retired professionals.
\end{abstract}

KEY WORDS: Subjective Happiness, General Happiness, Wisdom, Retirees, Older Adults \& Senior Citizens

Received: Oct 18, 2017; Accepted: Nov 02, 2017; Published: Nov 25, 2017; Paper Id.: IJESRDEC201712

\section{INTRODUCTION}

The Research on aging has focused on the cognitive features of age-related changes and found that aging is a phenomenon of decline. Old age is associated with declines in many aspects of cognition, as well as with a variety of detrimental stereotypes of incompetence but, there is an aspect to it that "holds more promise than present reality may reveal": wisdom (Baltes and Staudinger, 2000).

The concept of wisdom has its roots in religion and philosophy (Baltes and Smith, 2008). Wisdom is a complex, multi-faceted construct, there is no consensus on its definition and several rating scales for assessing wisdom.

There are several major definitions of wisdom. The Berlin Wisdom Paradigm (Baltes\& Smith, 1990) defined wisdom as expert knowledge in the fundamental pragmatics of life that permits exceptional insight, judgment, and advice about complex and uncertain matters and expertise in the conduct and meaning of life.

It is not hard to find supporters of the idea that wisdom is important for happiness in the history of philosophy. The profession of philosophical counseling is which uses philosophical means, for treating everyday problems and difficulties. Marinoff (2003) argued that, philosophizing about life helps people to develop the practical wisdom that enables them to deal with life more efficiently.

An investigation conducted by Amir (2004) stated that studying philosophy sometimes leads to confusion or 
discouragement and that the search for wisdom through philosophical counseling might contribute to unhappiness. It can be very frustrating to acquire a better understanding of one's difficulty if one does not have the means to resolve it. Hence, wisdom or greater insight might harm happiness. Possible tensions between wisdom and happiness have been extensively debated in philosophy. Some regard wisdom as the 'supreme part of happiness', whereas other think that a more accurate and wiser view on reality might reduce happiness.

Analyzing a Dutch internet survey of 7037 respondents and discovered that wisdom and happiness were modestly positively related. In philosophy, wisdom is not only seen as a life-ability that might enhance happiness, but as a goal in itself and as such, wisdom might conflict with happiness by, first, increasing one's insight into life and, second, through the realization that other things might be more important than the pursuit of happiness (Feldman, 2008).

In a sample of 158 Canadian older adults, self-transcendent wisdom (Levenson et al. 2005) was positively related to the subjective happiness Scale (Lyubomirsky and Lepper 1999), even after controlling for self-actualization (Beaumont 2009).

Wisdom, then, increases with lived experiences, at point in life wisdom may hamper the happiness in life. To examine this question we have addressed three aspects a) association between age and subjective happiness b) role of subjective happiness on wisdom by studying the mean scores of wisdom in relation to subjective happiness level c) relationship between subjective happiness and wisdom of retired professionals. The below given methodology was adopted to study the relationship between subjective happiness and wisdom of retired professionals.

\section{METHODOLOGY}

\section{Sampling Procedure}

\section{Sampling Criteria}

Retired professional belonging to the age group of 61-75 years were selected for the study.

\section{Technique for Sample Selection}

Purposive sampling technique was adopted for the study (since persons are retired professionals belonging to the categories of teaching, research, administration, law and medical were included for the study).

\section{Size of the Sample}

Retired professionals about 180 members were selected for the study.

\section{MEASUREMENT TOOLS}

\section{Subjective Happiness Scale}

To find out the association between subjective happiness and wisdom, the investigator has used the "subjective happiness scale 'which was developed by Sonja Lyubomirsky and Heidi S. Lepper (1997). The scale is also known as general happiness scale. The scale was standardized, the internal consistency of the scale: 0.86 , test-retest reliability: 0.72 and convergent validity: 0.63 .

\section{Scale on Wisdom}

To measure the wisdom among retirees, a scale was developed by the investigator and standardized. The Cronbach's alpha of the scale was 0.81 . 
procedure

The retired professionals belonging to the age range of 61-75 years were purposively selected from the Hyderabad city to conduct the study. The collected data was coded and analyzed using Chi-square, ANOVA and Pearson correlation to identify the wisdom levels among retired professionals.

\section{RESULTS}

Table 1: Subjective Happiness of Retired Professionals Based on Age Group, Gender and Retired Occupation

\begin{tabular}{|c|c|c|c|c|c|c|c|}
\hline \multirow{2}{*}{ S.No } & \multirow{2}{*}{ Category } & \multicolumn{4}{|c|}{ Subjective happiness } & \multirow{2}{*}{ Chi square } & \multirow{2}{*}{ Probability } \\
\hline & & Happier & Less happier & Feeling down & Total $=180$ & & \\
\hline & \multicolumn{7}{|l|}{ Age Group } \\
\hline 1 & $61-65$ years & $29(59 \%)$ & $20(41 \%)$ & -- & $49(27 \%)$ & \multirow{4}{*}{$2.602 \mathrm{~ns}$} & \multirow{4}{*}{0.63} \\
\hline 2 & $66-70$ years & $80(68 \%)$ & $36(31 \%)$ & $2(1 \%)$ & $118(66 \%)$ & & \\
\hline 3 & $71-75$ years & $9(69 \%)$ & $4(31 \%)$ & -- & $13(7 \%)$ & & \\
\hline & Total $=180$ & $118(66)$ & $60(33)$ & $2(1)$ & $180(100)$ & & \\
\hline
\end{tabular}

Significance at $(\mathrm{P}<0.05), * *$ Significance at $(\mathrm{P}<0.05)$, NS- Not Significant

The table-1 gives the details of association between subjective happiness and retired professional's age. It was observed from the table that out of three categories, chi-square value was not significant, it means age groups and subjective happiness are not significantly associated. Though there were no significant differences on happier category, almost equal percent of the sample from two age groups i.e. (69\%) of 71-75 years and (68\%) of 66-70 years and (59\%) of 61-65 years old retirees were found.

It shows that the sample from first age group (61-65 year) were found more on less happy category compared to the last two age groups (66-70 years and 71-75 years). The last age group retirees (71-75 years) were happier than the first two age groups (61-65 and 66-70 years). It indicates that as increases in age there was also slight increase in happiness. This might be due to the factors such as supporting family relationships, financial status, satisfaction with life may play a major role in increase of happiness.

This finding was in line with the survey conducted by Arthur Stone (2008) in his study found that people generally become happier and experience less worry after age sixty five. In fact, it was found that by the age of eighty-five, people are happier with their life than they were at eighteen.

Table 2: Mean Differences in Wisdom Based on Subjective Happiness of Retired Professionals

\begin{tabular}{|c|c|c|c|c|c|c|}
\hline S.No & Dimension & $\begin{array}{l}\text { Subjective } \\
\text { Happiness }\end{array}$ & Means & SD & F value & $\operatorname{Pr}>\mathbf{F}$ \\
\hline \multirow{3}{*}{1} & \multirow{3}{*}{ Self-knowledge } & Happier & $38.98 \mathrm{bc}$ & 4.15 & \multirow{3}{*}{$5.33 * *$} & \multirow{3}{*}{0.0056} \\
\hline & & Less Happier & $36.93 a$ & 3.95 & & \\
\hline & & Feeling Down & $36.00 \mathrm{ab}$ & 2.83 & & \\
\hline \multirow{3}{*}{2} & \multirow{3}{*}{ Life knowledge } & Happier & $40.17 \mathrm{a}$ & 3.26 & \multirow{3}{*}{$2.93^{*}$} & \multirow{3}{*}{0.06} \\
\hline & & Less Happier & $38.92 \mathrm{a}$ & 3.53 & & \\
\hline & & Feeling Down & $38.50 \mathrm{a}$ & 0.71 & & \\
\hline \multirow{3}{*}{3} & \multirow{3}{*}{ Life skills } & Happier & $39.84 b c$ & 2.91 & \multirow{3}{*}{$5.88 * *$} & \multirow{3}{*}{0.0034} \\
\hline & & Less Happier & $38.18 \mathrm{a}$ & 3.44 & & \\
\hline & & Feeling Down & $38.00 \mathrm{ab}$ & 1.41 & & \\
\hline 4 & Judgement & Happier & $42.41 \mathrm{a}$ & 2.01 & $1.87 \mathrm{NS}$ & 0.16 \\
\hline
\end{tabular}




\begin{tabular}{|c|c|c|c|c|c|c|}
\hline & & Less Happier & $41.73 \mathrm{a}$ & 2.94 & & \\
\hline & & Feeling Down & $41.00 \mathrm{a}$ & 1.41 & & \\
\hline \multirow{3}{*}{5} & \multirow{3}{*}{ Emotional maturity } & Happier & $40.14 b c$ & 2.88 & \multirow{3}{*}{$6.47 * *$} & \multirow{3}{*}{0.0019} \\
\hline & & Less Happier & $38.43 \mathrm{a}$ & 3.22 & & \\
\hline & & Feeling Down & $40.00 \mathrm{ab}$ & 1.41 & & \\
\hline \multirow{3}{*}{6} & \multirow{3}{*}{ Reflection } & Happier & $35.36 \mathrm{a}$ & 2.42 & \multirow{3}{*}{$1.41 \mathrm{NS}$} & \multirow{3}{*}{0.25} \\
\hline & & Less Happier & $35.82 \mathrm{a}$ & 2.4 & & \\
\hline & & Feeling Down & $37.50 \mathrm{a}$ & 0.71 & & \\
\hline \multirow{3}{*}{7} & \multirow{3}{*}{$\begin{array}{l}\text { Interpersonal } \\
\text { understanding- } \\
\text { Altruism }\end{array}$} & Happier & $34.57 \mathrm{bc}$ & 3.42 & \multirow{3}{*}{$6.10 * *$} & \multirow{3}{*}{0.0027} \\
\hline & & Less Happier & $32.78 \mathrm{a}$ & 3.14 & & \\
\hline & & Feeling Down & $32.00 \mathrm{ab}$ & 0 & & \\
\hline \multirow{3}{*}{8} & \multirow{3}{*}{$\begin{array}{l}\text { Interpersonal } \\
\text { understanding- } \\
\text { Inspirational } \\
\text { engagement }\end{array}$} & Happier & $33.16 \mathrm{bc}$ & 3.58 & \multirow{3}{*}{$8.28 * *$} & \multirow{3}{*}{0.0004} \\
\hline & & Less Happier & $30.80 \mathrm{a}$ & 3.97 & & \\
\hline & & Feeling Down & $34.00 \mathrm{ab}$ & 0 & & \\
\hline \multirow{3}{*}{9} & \multirow{3}{*}{ Wisdom } & Happier & $304.62 \mathrm{bc}$ & 15.8 & \multirow{3}{*}{$8.47 * *$} & \multirow{3}{*}{0.0003} \\
\hline & & Less Happier & $293.60 \mathrm{a}$ & 19.1 & & \\
\hline & & Feeling Down & $297.00 \mathrm{ab}$ & 7.07 & & \\
\hline
\end{tabular}

*Significance at $(\mathrm{P}<0.05),{ }^{* *}$ Significance at $(\mathrm{P}<0.05)$, NS- Not Significant

The table above depicts the details of mean differences in wisdom, related to subjective happiness score categories. There were highly significant differences in mean scores of wisdom in relation to subjective happiness score categories.

Similarly there were also significant differences in means of wisdom's dimensions namely, self-knowledge, lifeknowledge, life skills, emotional maturity, altruism and inspirational engagements. The high mean score on wisdom was seen on subjective happiness 'happier' score level and the low mean score was seen on 'less happy' score level.

It seems like, the retired professionals who perceived themselves as 'happier' had high mean score on wisdom and its related aspects than the retirees who regarded themselves as 'less happier' and 'feeling down'. This shows subjective happiness has a significant influence on wisdom of retirees.

This might be due to the reasons that happier retired professionals might be good at shaping everyday life to suit their needs by carefully cropping their social networks or looking at life in relative terms by maintaining good cognitive control and better abilities to regulate emotions, which is the foundation for wiser behaviour.

The findings of the study was supported by a 2007 University of Chicago study finds the interlink between 
happiness and wisdom says that happiness is the main objective of human existence. Happiness positively associated with the absence of negative emotions, the presence of positive emotions, life satisfaction, social engagement and objectives in life, however these characteristics are important for a person to become wise. Thus subjective happiness has a vital role in facilitating the wise abilities among retired professionals.

Table 3: Relationship Between Subjective Happiness and Wisdom of Retired Professionals

\begin{tabular}{|c|l|c|c|}
\hline S.No & \multicolumn{1}{|c|}{ Dimensions } & $\begin{array}{c}\text { Correlation } \\
\text { coefficient }\end{array}$ & Probability \\
\hline 1 & Self-Knowledge & $.251^{* *}$ & 0.001 \\
\hline 2 & Life-knowledge & $.173^{*}$ & 0.02 \\
\hline 3 & Life skills & $.218^{* *}$ & 0.003 \\
\hline 4 & Judgement & $.196^{* *}$ & 0.008 \\
\hline 5 & $\begin{array}{l}\text { Emotional } \\
\text { Maturity }\end{array}$ & $.206^{* *}$ & 0.005 \\
\hline 6 & Reflection & $.171^{*}$ & 0.022 \\
\hline 7 & Altruism & $.214^{* *}$ & 0.004 \\
\hline 8 & $\begin{array}{l}\text { Inspirational } \\
\text { Engagements }\end{array}$ & $.213^{* *}$ & 0.004 \\
\hline 9 & Wisdom & $.259^{* *}$ & .000 \\
\hline
\end{tabular}

From the results it was also observed that, there was a highly positive and significant relationship between subjective happiness and wisdom at $1 \%$ level of significance. It means as increase in happiness there is also increased in wisdom.

It was also noticed from the table that happiness was highly correlated with self-knowledge, life skills, emotional maturity altruism and inspirational engagements at $1 \%$ level of significance and also significantly related with lifeknowledge and reflection dimensions at $5 \%$ level of significance.

This might be due to the reason that, the retired professionals might be happier because of fulfilled goals, high financial status and high educational background might assisted them to have balanced mental health status which helped them to be happier. With stress free mind the retired professionals might be focused and become wise by increased abilities on all the aspects related to the wisdom.

\section{CONCLUSIONS}

The findings of analysis was revealed that age groups and subjective happiness were not significantly associated but there was a slight increase in happiness level with increasing of age. The analysis of variance results indicated that the retirees who are happier had high mean score on all the components of wisdom than the retirees who are less happy. Further the Pearson correlation shown that subjective happiness was positively and significantly related with the wisdom of retired professionals. Finally it can be concluded that the retirees who are happier were wiser because with happiness the retirees might able to use their experience, abilities and knowledge in a meaningful way. Hence to become wise, happiness is one of the important aspect where the human beings uses their fullest strengths.

\section{REFERENCES}

1. Amir, L. B. 2004. Three questionable assumptions of philosophical counseling. International Journal of Philosophical Practice, 2(1), 9-18. 
2. Baltes, P.B and Smith, J. 2008. Toward a psychology of wisdom and its ontogenesis. In: Sternberg, RJ., editor. Wisdom: Its nature, origins, and development. Cambridge University Press; New York.

3. Baltes, P. B and Staudinger, U. M. 2000. Wisdom: A meta-heuristic (pragmatic) to orchestrate mind and virtue toward excellence. American Psychologist. 55: 122-136.

4. Beaumont, S. L. 2009. Identity processing and personal wisdom: An information-oriented identity style predicts selfactualization and self-transcendence. Identity: An International Journal of Theory and Research. 9(2): 95-115.

5. Feldman, F. 2008. Whole life satisfaction concepts of happiness. Theoria, Journal of Happiness Studies.74 (3), $219-238$.

6. Levenson, M. R., Jennings, P. A., Aldwin, C. M and Shiraishi, R. W. 2005. Self transcendence: Conceptualization and measurement. International Journal of Aging \& Human Development. 60: 127-143.

7. Lyubomirsky, S and Lepper, H. S. 1999. A measure of subjective happiness: Preliminary reliability and construct validation. Social Indicators Research. 46(2): 137-155.

8. Marinoff, L. 2003. The big questions: How philosophy can change your life. New York, NY: Bloomsbury. 